
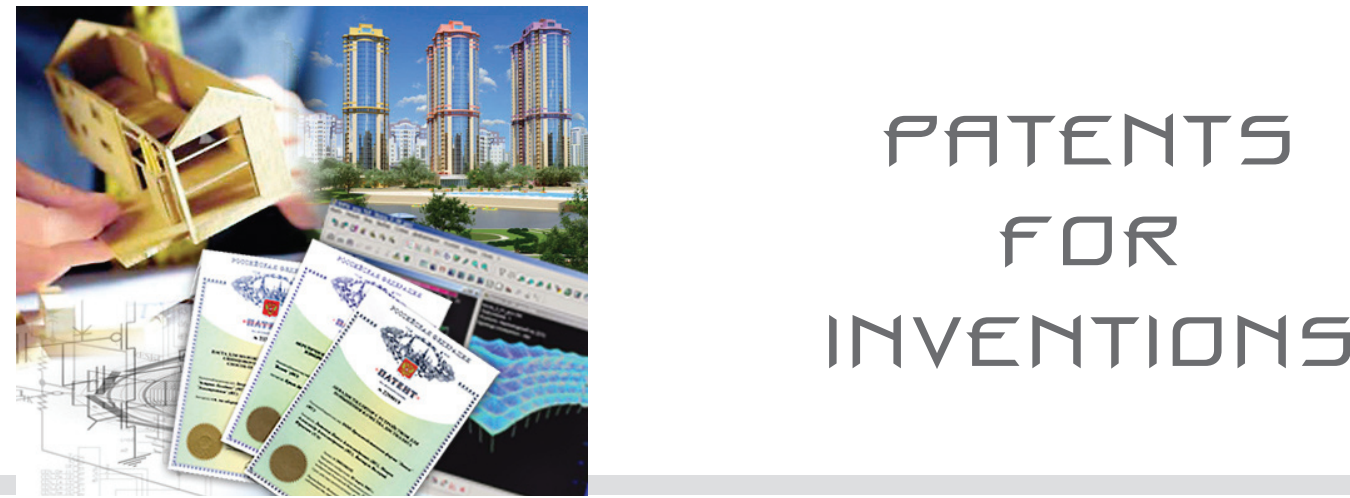

UDC $608 ; 69.001 .5$

Author: VLASOV Vladimir Alexeevich, Ph.D. in Engineering, Expert, International Academy of Engineering;

Gazetny per., block 9, bld.4, Moscow, 125009, Russian Federation, e-mail: info@nanobuild.ru

\title{
THE REVIEW OF PATENTS IN THE AREA OF NANOTECHNOLOGIES AND NANOMATERIALS.
}

PART 3.

\section{ExTENDEd Abstract:}

The inventions in the area of nanotechnologies and nanomaterials produce a profound effect in construction, housing and communal services and adjacent economic fields.

The invention «The method to produce body of oriented carbon nanotubes on the surface of base plate (RU 2561616)» refers to the technologies for production of body of carbon nanotubes on the surface of base plate. The flow of actuation gas is formed in the reaction chamber. The flow contains carrying gas, gas hydrocarbon and predecessor of catalyst for synthesis of carbon nanotubes. In some cases, when implementing invention, the flow of inert gas is directed to the surface of the base plate. This gas flow shades the zone of synthesis of carbon nanotubes from air when its pressure exceeds the pressure of actuation gas flow. The method provides the body of oriented carbon nanotubes on the base plates with big surface: up to several square metres.

The invention «Composition of mixture for asphaltic concrete (RU 2561435)» refers to the construction production in highway industry and can be applied in manufacture of asphaltic concrete including nanotechnologies.

The specialists may be also interested in the following nanotechnological inventions: the method to modify carbon nanomaterials ( $R U$ 2548083); nanofi- 
ber polymer material (RU 2543377); the method to produce nanosuspensions for manufacture of polymer nanocomposite (RU 2500695); the method to strengthen metal products to obtain nanostructured surface layers (RU 2527511); the method to form heat-resistant nanocomposite coating on the surface of the products made of heat-resistant nickel alloys (RU 2549813); the method to apply nanodiamond material by means of combined electromechanical treatment (RU 2530432); the method to produce soot with content of fullerens and nanotubes made of gas carbon raw material (RU 2531291); the method to produce powders of zinc oxide with surface modification for usage in construction sealing materials (RU 2505379); high resource electric arc generator of low-temperature plasma with protective nanostructured carbon coatings of electrodes (RU 2541349); the method to produce laminated nanomaterial (RU 2530456); fine-dispersed organic suspension of metal/carbon nanocomposite and the method to produce it (RU 2527218); the method to produce metal nanopowders with increased stored energy (RU 2535109) et al.

Key words: nanotechnologies in construction, nanomaterials, nanotubes, nanocomposite, nanostructured coating, nanopowder, nanofiber polymer material.

MACHINE-READABLE INFORMATION ON CC-LICENSES (HTML-CODE) IN METADATA OF THE PAPER

$<$ a rel=»license» href=»http://creativecommons.org/licenses/by/4.0/»><img alt=» Лицензия Creative Commons» style=»border-width:0» src=»https://i.creativecommons.org/l/by/4.0/88x31.png» / $></ \mathrm{a}><$ br $/>$ Произведение "<span xmlns:dct=»http://purl.org/dc/terms/» href=" http://purl.org/dc/dcmitype/Text» property=»dct:title» rel=»dct:type» $>$ The review of patents in the area of nanotechnologies and nanomaterials. Part 3. $</$ span $>$ » созданное автором по имени $<$ a xmlns:cc $=»$ http://creativecommons.org/ns\#» href=»Nanotehnologii v stroitel'stve = Nanotechnologies in Construction. 2015, Vol. 7, no. 5, pp. 64-82. DOI: dx.doi.org/10.15828/2075-8545-2015-7-5- 64-82.» property=»cc:attributionName» rel=»cc:attributionURL»>Vlasov V.A. $<$ /a $>$, публикуется на условиях $<$ a rel=»license» href=»http://creativecommons. org/licenses/by/4.0/»>лицензии Creative Commons «Attribution» ( «Атрибуция») 4.0 Всемирная </a $>$. $<$ br $/>$ Основано на произведении с < a xmlns:dct=»http://purl.org/dc/terms/» href=»http://nanobuild.ru/en_EN/nanobuild-5-2015/» rel=»dct:source»>http://nanobuild.ru/en_EN/nanobuild-5-2015/</a $>$. $<$ br />Разрешения, выходящие за рамки данной лицензии, могут быть доступны на странице <a xmlns:cc=»http://creativecommons.org/ns\#»href=»info@nanobuild.ru» rel=»cc:morePermissions»>info@nanobuild.ru</a $>$.

\section{References:}

1. Patents and inventions registered in RF and USSR [Electronic source]. - Access mode: http://www.findpatent.ru/patent/256/2561616.html (date of access: 25.08.15).

2. Patents and inventions registered in RF and USSR [Electronic source]. - Access mode: 
http://www. findpatent.ru/patent/256/2561614.html (date of access: 25.08.15).

3. Patents and inventions registered in RF and USSR [Electronic source]. - Access mode: http://www.findpatent.ru/patent/256/2561435.html (date of access: 25.08.15).

4. Patents and inventions registered in RF and USSR [Electronic source]. - Access mode: http://www.findpatent.ru/patent/256/2561379.html (date of access: 25.08.15).

5. Patents and inventions registered in RF and USSR [Electronic source]. - Access mode: http://www.findpatent.ru/patent/256/2561343.html (date of access: 25.08.15).

6. Patents and inventions registered in RF and USSR [Electronic source]. - Access mode: http://www.findpatent.ru/patent/256/2561267.html (date of access: 25.08.15).

7. Patents and inventions registered in RF and USSR [Electronic source]. - Access mode: http://www.findpatent.ru/patent/256/2561170.html (date of access: 25.08.15).

8. Patents and inventions registered in RF and USSR [Electronic source]. - Access mode: http://www.findpatent.ru/patent/256/2560898.html (date of access: 25.08.15).

9. Patents and inventions registered in RF and USSR [Electronic source]. - Access mode: http://www.findpatent.ru/patent/256/2560722.html (date of access: 25.08.15).

10. Patents and inventions registered in RF and USSR [Electronic source]. - Access mode: http://www.findpatent.ru/patent/256/2560382.html (date of access: 25.08.15).

11. Patents and inventions registered in RF and USSR [Electronic source]. - Access mode: http://www.findpatent.ru/patent/256/2560031.html (date of access: 25.08.15).

12. Patents and inventions registered in RF and USSR [Electronic source]. - Access mode: http://www.findpatent.ru/patent/255/2559481.html (date of access: 25.08.15).

13. Patents and inventions registered in RF and USSR [Electronic source]. - Access mode: http://www.findpatent.ru/patent/255/2559351.html (date of access: 25.08.15).

14. Patents and inventions registered in RF and USSR [Electronic source]. - Access mode: http://www.findpatent.ru/patent/255/2559284.html (date of access: 25.08.15).

15. Patents and inventions registered in RF and USSR [Electronic source]. - Access mode: http://www.findpatent.ru/patent/255/2559093.html (date of access: 25.08.15).

16. Vlasov V.A. The review of patents in the area of nanotechnologies and nanomaterials. Part 2. Nanotehnologii v stroitel'stve $=$ Nanotechnologies in Construction. 2015, Vol. 7, no. 4, pp. 59-79. DOI: dx.doi.org/10.15828/2075-8545-2015-7-4-59-79.

17. Patents and inventions registered in RF and USSR [Electronic source]. - Access mode: http://www.findpatent.ru/patent/254/2543377.html (date of access: 25.08.15).

18. Patents and inventions registered in RF and USSR [Electronic source]. - Access mode: http://www.findpatent.ru/patent/250/2500695.html (date of access: 25.08.15).

19. Vlasov V.A. The inventions in nanotechnological area increase the efficiency of construction, housing and communal services and adjacent economic fields. Nanotehnologii $\mathrm{v}$ stroitel'stve $=$ Nanotechnologies in Construction. 2014, Vol. 6, no. 5, pp. 93-113. DOI: dx.doi.org/10.15828/2075-8545-2014-6-5-93-113.

20. Vlasov V.A. The review of patents in the area of nanotechnologies and nanomaterials. Part 2. Nanotehnologii v stroitel'stve = Nanotechnologies in Construction. 2015, Vol. 7, no. 4, pp. 59-79. DOI: dx.doi.org/10.15828/2075-8545-2015-7-4-59-79. 
21. Patents and inventions registered in RF and USSR [Electronic source]. - Access mode: http://www.findpatent.ru/patent/253/2530432.html (date of access: 25.08.15).

22. Patents and inventions registered in RF and USSR [Electronic source]. - Access mode: http://www.findpatent.ru/patent/253/2531291.html (date of access: 25.08.15).

23. Patents and inventions registered in RF and USSR [Electronic source]. - Access mode: http://www.findpatent.ru/patent/250/2505379.html (date of access: 25.08.15).

24. Vlasov V.A. The review of patents in the area of nanotechnologies and nanomaterials. Part 1. Nanotehnologii v stroitel'stve = Nanotechnologies in Construction. 2015, Vol. 7, no. 2, pp. 89-114. DOI: dx.doi.org/10.15828/2075-8545-2015-7-2-89-114.

25. Vlasov V.A. The nanotechnological inventions raise competitive ability of the products. Nanotehnologii v stroitel'stve $=$ Nanotechnologies in Construction. 2014, Vol. 6, no. 6, pp. 58-78. DOI: dx.doi.org/10.15828/2075-8545-2014-6-6-58-78.

26. Patents and inventions registered in RF and USSR [Electronic source]. - Access mode: http://www.findpatent.ru/patent/252/2527218.html (date of access: 25.08.15).

27. Vlasov V.A. Nanotechnological inventions and nanomaterials produce a profound effect in different areas of economy. Nanotehnologii v stroitel'stve $=$ Nanotechnologies in Construction. 2015, Vol. 7, no. 1, pp. 82-104. DOI: dx.doi.org/10.15828/2075-8545-2015-71-82-104.

28. Patents and inventions registered in RF and USSR [Electronic source]. - Access mode: http://www.findpatent.ru/patent/252/2527511.html (date of access: 25.08.15).

Dear Colleagues!

THE REFERENCE TO THIS PAPER HAS THE FOLLOWING CITATION FORMAT:

Vlasov V.A. The review of patents in the area of nanotechnologies and nanomaterials. Part 3. Nanotehnologii v stroitel'stve = Nanotechnologies in Construction. 2015, Vol. 7, no. 5, pp. 64-82. DOI: dx.doi.org/10.15828/2075-8545-2015-7-564-82. (In Russian). 

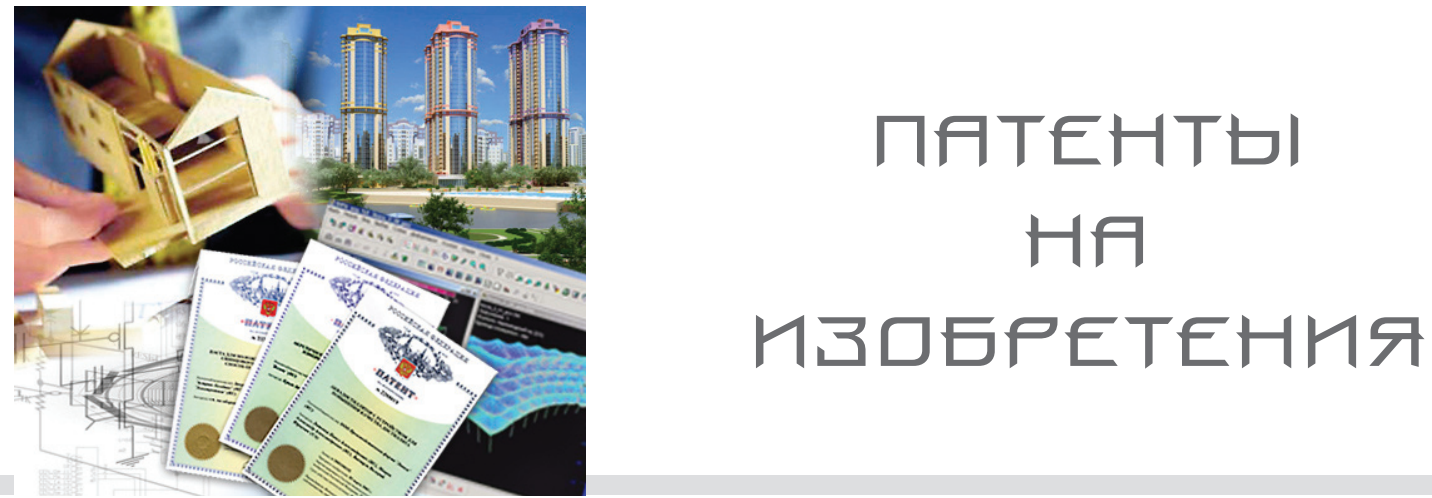

УдК 608; 69.001.5

Автор: ВЛАСОВ Владимир Алексеевич, канд. техн. наук, эксперт, Международная инженерная академия; Газетный пер., д. 9, стр. 4, г. Москва, 125009, Российская Федерация, e-mail: info@nanobuild.ru

\section{ОБЗОР ИЗОБРЕТЕНИЙ В ОБЛАСТИ НАНОТЕХНОЛОГИЙ И НАНОМАТЕРИАЛОВ. ЧACTЬ 3}

\section{АННОТАЦИЯ К СТАТЬЕ (АВТОРСКОЕ РЕЗЮМЕ, РЕФЕРАТ):}

Изобретения в области нанотехнологий и наноматериалов позволяют в строительстве, жилищно-коммунальном хозяйстве, смежных отраслях экономики добиться значительного эффекта.

Изобретение «Способ получения массивов ориентированных углеродных нанотрубок на поверхности подложки (RU 2561616)» относится к технологиям получения массивов углеродных нанотрубок на поверхности подложки. В реакционной камере формируют поток рабочего газа, содержащего несущий газ, газообразный углеводород и предшественник катализатора для синтеза углеродных нанотрубок. В частном случае осуществления изобретения на поверхность подложки дополнительно направляют поток инертного газа, экранирующий зону синтеза углеродных нанотрубок от воздуха, при его давлении, превышающем давление потока рабочего газа. Обеспечивается получение массивов ориентированных углеродных нанотрубок на подложках, имеющих поверхности большой площади - до нескольких квадратных метров.

Изобретение «Состав смеси для асфальтобетона (RU 2561435)» относится к области строительного производства в автодорожной отрасли и может быть применено при изготовлении асфальтобетона, в том числе с использованием нанотехнологий. 
Также представляют интерес для специалистов следующие изобретения в области нанотехнологий: способ модифицирования углеродных наноматериалов (RU 2548083); нановолокнистый полимерный материал (RU 2543377); способ приготовления наносуспензии для изготовления полимерного нанокомпозита (RU 2500695); способ упрочнения металлических изделий с получением наноструктурированных поверхностных слоев (RU 2527511); способ формирования жаростойкого нанокомпозитного покрытия на поверхности изделий из жаропрочных никелевых сплавов (RU 2549813); способ нанесения наноалмазного материала комбинированной электромеханической обработкой (RU 2530432); способ получения сажи, содержащей фуллерены и нанотрубки, из газообразного углеводородного сырья (RU 2531291); способ получения нанопорошков оксида цинка с поверхностным модифицированием для использования в строительных герметиках (RU 2505379); высокоресурсный электродуговой генератор низкотемпературной плазмы с защитным наноструктурированным углеродным покрытием электродов (RU 2541349); способ получения слоистого наноматериала (RU 2530456); тонкодисперсная органическая суспензия металл/углеродного нанокомпозита и способ ее изготовления (RU 2527218); способ получения нанопорошков металлов с повышенной запасенной энергией (RU 2535109) и др.

Ключевые слова: нанотехнологии в строительстве, наноматериалы, нанотрубки, нанокомпозит, наноструктурированное покрытие, нанопорошок, нановолокнистый полимерный материал.

МАШИНОЧИТАЕМАЯ ИНФОРМАЦИЯ О CC-ЛИЦЕНЗИИ В МЕТАДАННЫХ СТАТЬИ (HTML-КОД):

$<$ a rel=»license» href=»http://creativecommons.org/licenses/by/4.0/»><img alt=» Лицензия Creative Commons» style=»border-width:0» src=»https://i.creativecommons.org/1/by/4.0/88x31.png» $/></ \mathrm{a}><$ br $/>$ Произведение "<span xmlns:dct=»http://purl.org/dc/terms/» href=»http://purl.org/dc/dcmitype/Text» property=»dct:title» rel=»dct:type»>0бзор изобретений в области нанотехнологий и наноматериалов. Часть $3</$ span $>$ » созданное автором по имени <a xmlns:cc=»http://creativecommons.org/ns\#» href=»Нанотехнологии в строительстве. -2015. - Том 7, № 5. - C. 64-82. - DOI: dx.doi.org/10.15828/2075-8545-2015-7-5-64-82.» property=»cc:attributionName» rel=»cc:attributionURL»>Bласов В.А. $</ \mathrm{a}>$, публикуется на условиях $<$ a rel=»license» href=»http://creativecommons org/licenses/by/4.0/»> лицензии Creative Commons «Attribution» ( «Атрибуция») 4.0 Всемирная </a $>$. $<$ br $/>$ Основано на произведении с < a xmlns:dct=»http://purl.org/dc/terms/» href=»http://nanobuild.ru/ru RU/nanobuild-5-2015/" rel=»dct:source»>http://nanobuild.ru/ru_RU/nanobuild-5-2015/</a $>$. $<$ br />Pазрешения, выходящие за рамки данной лицензии, могут быть доступны на странице $<$ a xmlns:cc=» http://creativecommons.org/ns\#» href=»info@nanobuild.ru» rel=»cc:morePermissions»>info@nanobuild.ru</a>. 


\section{Способ получения массивов ориентированных углеродных нанотрубок на поверхности подложки (RU 2561616)}

Изобретение относится к технологиям получения массивов углеродных нанотрубок на поверхности подложки. В реакционной камере формируют поток рабочего газа, содержащего несущий газ, газообразный углеводород и предшественник катализатора для синтеза углеродных нанотрубок. Поток рабочего газа направляют на поверхность подложки со скоростью 100-1000 м/с. Вдоль потока рабочего газа направляют инфракрасное импульсное лазерное излучение с частотой импульсов $5-100$ кГц и энергией импульсов 0,05-0,5 Дж для его активации и локального нагрева поверхности подложки до 600-1000 ${ }^{\circ} \mathrm{C}$. Упомянутую реакционную камеру перемещают над поверхностью подложки. В частном случае осуществления изобретения на поверхность подложки дополнительно направляют поток инертного газа, экранирующий зону синтеза углеродных нанотрубок от воздуха, при его давлении, превышающем давление потока рабочего газа. Обеспечивается получение массивов ориентированных углеродных нанотрубок на подложках, имеющих поверхности большой площади - до нескольких квадратных метров [1].

\section{Способ получения ультрадисперсного порошка карбида титана (RU 2561614)}

Изобретение относится к области порошковой металлургии и может быть использовано при изготовлении твердых сплавов, режущего инструмента и износостойких покрытий. Водный раствор сульфата титанила нейтрализуют до $\mathrm{pH}$ 10-12 раствором гидроксида аммиака/натрия в присутствии сажи с получением порошка. Порошок прессуют и проводят обработку микроволновым излучением с частотой 2450-3000 МГц при мощности 700-1200 Вт в токе аргона со скоростью 7-8 л/час в три стадии, причем на первой стадии со скоростью $15^{\circ} \mathrm{C} /$ мин до $500^{\circ} \mathrm{C}$, на второй - со скоростью $10^{\circ} \mathrm{C} /$ мин до $700^{\circ} \mathrm{C}$ и на третьей - со скоростью $5^{\circ} \mathrm{C} /$ мин до $1300^{\circ} \mathrm{C}$ и с выдержкой в течение 60-70 мин. Обеспечивается получение ультрадисперсного порошка карбида титана с размером частиц около 250 нм [2]. 


\section{Состав смеси для асфальтобетона (RU 2561435)}

Изобретение относится к области строительного производства в автодорожной отрасли и может быть применено при изготовлении асфальтобетона, в том числе с использованием нанотехнологий. Состав смеси для асфальтобетона, включающий щебень, песок, битум и углеродную добавку, содержит щебень фр. 5-15 мм, битум БНД 90/130, в качестве песка - кварц-полевошпатовый песок с модулем крупности 3 , в качестве углеродной добавки - углеродные наноматериалы, полученные как побочный продукт при плазменной обработке угля в плазменном реакторе и имеющие луковичные и нитевидные углеродные структуры, с предварительным их распределением в подогретом до $130-140^{\circ} \mathrm{C}$ битуме в количестве $0,03-0,06$ мас.\% от указанной смеси, и дополнительно минеральный порошок МП-1 при следующем соотношении компонентов, мас. \% : указанный щебень $-42-44$, указанный песок $-48-50$, минеральный порошок МП-1 - 8-9, указанный битум - 5,4-5,6 (сверх минеральной части). Технический результат - повышение прочности асфальтобетона на сжатие при $20^{\circ} \mathrm{C}$ и при $50^{\circ} \mathrm{C}$, снижение расхода углеродных наноматериалов в составе асфальтобетона [3].

\section{Наночастицы антипирена гидроксида магния и способ их производства (RU 2561379)}

Изобретение относится к химической технологии. На первой стадии производства наночастиц антипирена гидроксида магния осуществляют взаимодействие водного раствора хлорида магния с щелочным компонентом при температуре не выше $100^{\circ} \mathrm{C}$ и мольном отношении ионов $\mathrm{OH}^{-}$: $\mathrm{Mg}^{++}$в пределах $(1,9-2,1): 1$. На второй стадии проводят гидротермальную перекристаллизацию частиц при температуре $120-220^{\circ} \mathrm{C}$, давлении от 0,18 до 2,3 МПа в течение 2-24 ч. При этом реакционную массу подвергают периодическим гидроударам перегретым паром при $160-240^{\circ} \mathrm{C}$ и давлении от 0,6 до 3,3 МПа. Получают наночастицы антипирена гидроксида магния, имеющие гексагональную пластинчатую структуру и удельную площадь поверхности не более $20 \mathrm{~m}^{2} /$ г. Средний диаметр вторичных частиц - не более 2 мкм. Диаметр $10 \%$ вторичных частиц - не более 0,8 мкм, а диаметр $90 \%$ вторичных частиц - не более 5 мкм. Про- 
дольный размер первичных частиц - от 150 до 900 нм, толщина - от 15 до 150 нм. Наночастицы могут быть поверхностно обработаны. Изобретение позволяет достичь более равномерного распределения частиц антипирена гидроксида магния в полимерных матрицах без снижения их механических свойств и технологичности переработки [4].

\section{Лазерный формирователь объемных нанокомпозитов (RU 2561343)}

Изобретение относится к средствам для изготовления материалов, позволяющих компенсировать врожденные пороки развития человека и животных. Предложенный лазерный формирователь объемных нанокомпозитов содержит столик, на котором установлен сосуд для размещения водно-белковой дисперсии углеродных нанотрубок, оптически сопряженный с оптоволоконным световодом и пирометрическим измерителем температуры и сопряженный с термопарой. При этом с оптоволоконным световодом оптически сопряжены основной и пилотный лазерные излучатели. Кроме того, в состав предложенного устройства введен дополнительный модуль, в котором закреплены пирометрический измеритель температуры, сопряженный с термопарой, и оптоволоконный световод. Предложенное изобретение позволяет повысить качество изготавливаемых нанокомпозитов и упростить компоновку входящих частей установки лазерного формирователя для изготовления данных нанокомпозитов [5].

\section{Нанопористая полимерная пена, имеющая высокую пористость (RU 2561267)}

Изобретение относится к изделиям из нанопористого полимерного пеноматериала и способу получения изделий из полимерного пеноматериала. Изделие из полимерного пеноматериала включает матрицу из термопластичного полимера, заключающую множество пор в ней. Матрица из термопластичного полимера содержит диспергированные в ней частицы зародышеобразующей добавки наноразмера, которые имеют, по меньшей мере, два ортогональных размера, длина которых меньше 30 нанометров. Изобретение обеспечивает оптимальные теплоизоляционные свойства [6]. 


\section{Эластомерные нанокомпозиты, композиции нанокомпозитов и способы их получения (RU 2561170)}

Изобретение относится $\mathrm{\kappa}$ эластомерному нанокомпозиту на основе C4-С7-изоолефина, обладающего улучшенными рабочими характеристиками и характеристиками смешивания. Нанокомпозит содержит сополимер, образованный из, по меньшей мере, одного $\mathrm{C}_{4}$ $\mathrm{C}_{7}$-изоолефинового мономера и мультиолефинового мономера, и нанонаполнитель, содержащий смектитовую глину с поверхностно-активным веществом. При этом поверхностно-активное вещество обладает структурой $\left(R^{1} R^{2} R^{3} R^{4}\right) N^{+}$, в которой $R^{1}$ обозначает звено, образованное из бензила, которое может быть или не быть замещенным, в которой $\mathrm{R}^{2}$ выбран из группы, включающей $\mathrm{C}_{1}-\mathrm{C}_{26}$-алкилы, $\mathrm{C}_{2}-\mathrm{C}_{26}$-алкены и $\mathrm{C}_{3}-\mathrm{C}_{26}$ арилы, и в которой $\mathrm{R}^{3}$ и $\mathrm{R}^{4}$ являются одинаковыми или разными и независимо выбраны из группы, включающей $\mathrm{C}_{9}-\mathrm{C}_{26}$-алкилы, $\mathrm{C}_{9}-\mathrm{C}_{26}$-алкены и $\mathrm{C}_{9}-\mathrm{C}_{26}$-арилы. Полученные нанокомпозиты обладают улучшенными механическими и барьерными характеристиками при использовании в изделиях, для которых необходима непроницаемость, таких, как герметизирующие слои покрышек, камеры, диафрагмы вулканизатора шин, шланги, медицинские пробки, непроницаемые листы и другие аналогичные изделия [7].

\section{Установка для обработки нанокомпозитов в водородной плазме (RU 2560898)}

Изобретение относится к вакуумно-плазменной обработке нанокомпозитов. Установка для обработки нанокомпозитов в водородной плазме содержит СВЧ-печь, установленный внутри СВЧ-печи кварцевый реактор для размещения в нем нанокомпозитов, состоящий из корпуса в виде полого цилиндра из кварцевого стекла и установленных на его торцах фланцев с хвостовиками для соединения с вакуумными шлангами, один из которых предназначен для подачи водорода в кварцевый реактор и снабжен натекателем, а другой - для вакуумирования СВЧпечи и реактора. Один из фланцев выполнен с возможностью его снятия, при этом каждый из фланцев выполнен составным и состоит из наружной оболочки, крышки, уплотнения и профилированной прокладки из 
кварцевого стекла. Наружная оболочка выполнена в виде полого двухступенчатого цилиндра с хвостовиком для вакуумного шланга и имеет наружную резьбу для установки на нее крышки и внутреннюю конусную поверхность для установки уплотнения в конический зазор между корпусом реактора и наружной оболочкой, профилированная прокладка выполнена с хвостовиком, входящим ответно в хвостовик наружной оболочки и взаимодействующим с ним своей наружной поверхностью, при этом внутренняя полость СВЧ-печи соединена с устройством для создания разрежения в указанной полости. Обеспечивается непрерывная обработка нанокомпозитов в водородной плазме [8].

\section{Наночастицы типа «ядро-оболочка», способ их синтеза и их применение (RU 2560722)}

Настоящее изобретение относится к способу синтеза наночастиц типа ядро-оболочка. Описан способ синтеза наночастиц типа ядрооболочка, включающий следующие стадии: синтез полимерной затравки в растворителе путем «живой» анионной дисперсионной полимеризации (при этом затравка включает моновиниловый мономер, поперечно-сшитый при помощи сшивающего агента для формирования ядра наночастицы, при этом ядро имеет средний диаметр от 5 до 10000 нанометров и содержит полимерные цепи с «живыми» концевыми группами); добавление стабилизатора для стабилизации затравки и предотвращения осаждения затравки из раствора; прививка и/или полимеризация частиц оболочки на «живые» концы ядра для формирования оболочки наночастицы (при этом затравка образована полимеризацией моновинилового мономера с использованием инициатора и поперечного сшивания полученного полимера со сшивающим мультивиниловым мономер агентом). Описаны также наночастицы типа ядро-оболочка, включающие: ядро, сформированное из полимерной затравки, которая включает частицы ядра моновинилового мономера, поперечно-сшитые при помощи сшивающего агента (при этом ядро имеет средний диаметр от 5 до 10000 нанометров); оболочку, содержащую частицы оболочки, присоединенные к ядру, при этом оболочка является главным образом несшитой; при этом затравка синтезирована «живой» анионной дисперсионной полимеризацией, причем затравка образована полимеризацией моновинилового моно- 
мера с использованием инициатора и поперечного сшивания полученного полимера со сшивающим мультивиниловым мономер агентом. Описан способ изготовления каучуковой композиции, включающий добавление наночастиц типа ядро-оболочка, полученных указанным выше способом, в вулканизируемую каучуковую матрицу. Также описан способ изготовления шин, включающий изготовление наночастиц типа ядро-оболочка указанным выше способом; добавление наночастиц типа ядро-оболочка в каучуковую смесь; фрормование каучуковой смеси в протектор шин и сборка шины с использованием протектора шины. Технический результат - получение наночастиц, обладающих низкой вязкостью, улучшенной смачиваемостью и улучшенной силой сцепления со снегом при включении в каучуковую матрицу [9].

\section{Способ изготовления полимерного композита на основе ориентированных углеродных нанотрубок} (RU 2560382)

Изобретение относится к композиционным материалам на основе углеродных нанотрубок. Предложен способ изготовления полимерного композита, включающий направленную ориентацию углеродных нанотрубок, заполнение межтрубочного пространства полимером и термообработку при температуре не выше температуры деструкции полимерного состава. В способе используют массив углеродных нанотрубок, выращенный методом MOCVD. Композиция для заполнения межтрубочного пространства не содержит растворителя. Заполнение массива ориентированных углеродных нанотрубок полимером осуществляют под воздействием вакуума. Изобретение обеспечивает повышенную прочность композита и возможность последующего фрормирования в нём сквозных нанопор [10].

\section{Электронные устройства, содержащие прозрачные проводящие покрытия, содержащие углеродные нанотрубки и композиты из нанопроводов, и способы их изготовления (RU 2560031)}

Солнечный элемент содержит: стеклянную подложку; первый проводящий слой на основе CNT, расположенный непосредственно 
или косвенно на стеклянной подложке; первый полупроводниковый слой в контакте с первым проводящим слоем на основе CNT; по меньшей мере, один поглощающий слой, расположенный непосредственно или косвенно на первом полупроводниковом слое; второй полупроводниковый слой, расположенный непосредственно или косвенно на, по меньшей мере, одном поглощающем слое; второй проводящий слой на основе CNT в контакте со вторым полупроводниковым слоем и контакт к тыльной поверхности, расположенный непосредственно или косвенно на втором проводящем слое на основе CNT. Изобретение обеспечивает возможность использования покрытий, которые достигают, соответствуют или превышают коэффициент пропускания 90\% в видимом свете и поверхностное сопротивление меньше чем 90 Ом /квадрат [11].

\section{Способ синтеза углеродных нанотрубок и устройство его осуществления (RU 2559481)}

Изобретение относится к области нанотехнологий и может быть использовано для получения углеродных наноструктур. Устройство для синтеза углеродных нанотрубок включает: камеру 1 , заполненную инертным газом, в которой расположены цилиндрические углеродосодержащие катод 2 и анод 3 , расположенные соосно, выполненные с возможностью их перемещения относительно друг друга в продольном направлении. Анод 3 разделен на два участка: рабочий 4, который расходуется в процессе синтеза, и отводящий 5. Отводящий участок 5 анода 3 выполнен с продольным цилиндрическим несквозным каналом 6. Отвод тепла от центральной части отводящего участка 5 анода 3 осуществляют с помощью медного цилиндрического теплоотводящего элемента 7 с закрепленным на свободном конце радиатором 8 до момента полного испарения рабочего участка анода 3. Углеродные нанотрубки получают в дуговом разряде между катодом 2 и анодом 3. Изобретение позволяет увеличивать содержание углеродных нанотрубок в катодном депозите за счет расширения и регулирования зоны действия температур, характерных для первой ионизации углерода, на свободном торце анода [12]. 


\section{Способ определения пространственного распределения плотности в нанослое (RU 2559351)}

Изобретение относится к области исследований слоистых наноструктур, в частности методике диагностики структуры наносистем. Способ определения пространственного распределения плотности атомов в нанослое состоит в том, что измеряют интенсивности отражения и пропускания через структуру нейтронов и интенсивности вторичных излучений, вызванных поглощением нейтронов в нанослое, при этом последовательно во времени формируют три разного типа зависимости плотности поляризованных нейтронов от координаты в глубь исследуемого слоя и от волнового вектора нейтронов, для этого используют трехслойную структуру, размещенную на подложке, в которой средний слой является исследуемым, следующий за исследуемым слой имеет потенциал взаимодействия нейтронов с веществом, превышающим потенциал исследуемого слоя. Слой, покрывающий исследуемый слой, является магнитным с потенциалом взаимодействия для поляризованных нейтронов в направлении вектора магнитной индукции больше, а для нейтронов, поляризованных противоположно - меньше потенциала взаимодействия исследуемого слоя. Технический результат - повышение точности определения распространений атомов изотопов, увеличение диапазона значений толщины исследуемого слоя [13].

\section{Способ получения наноразмерного карбида тантала термотрансформацией пентакис-(диметиламино)тантала (RU 2559284)}

Изобретение относится к получению нанодисперсного тугоплавкого карбида тантала, используемого в качестве наполнителя композиционных материалов, керамического теплозащитного покрытия, химически стойкого материала, материала для высокотемпературных керамоматричных композитов, и может быть использовано в области химической промышленности, авиационной и космической техники. Способ получения нанодисперсного тугоплавкого карбида тантала с образованием микросфер карбида тантала, состоящих из агломератов наночастиц, заключается в проведении ступенчатой термотрансформации раствора пентакис-(диметиламид)тантала в тетрадекане в инертной ат- 
мосфере в интервале температур $25-250^{\circ} \mathrm{C}$, осуществляемой путем нагрева реакционной массы до $160^{\circ} \mathrm{C}$ в течение часа и от $160^{\circ} \mathrm{C}$ до $250^{\circ} \mathrm{C}$ в течение трех часов, с получением тантал-азот-углеродсодержащего предкерамического полимера и его последующей термообработки путем нагрева до температуры $1100^{\circ} \mathrm{C}$ со скоростью $10^{\circ} \mathrm{C} /$ мин с выдержкой в инертной атмосфере в течение 3 часов. Технический результат - сокращение стадий процесса, простота аппаратурного оформления, возможность получения укрупненных партий продукта, использование одного компонента в качестве источника тантала и углерода [14].

\section{Солнечная энергетическая установка (RU 2559093)}

Изобретение относится к области энергетики, а именно к области использования солнечной энергии, и может быть применено при генерировании электрического тока с использованием энергии солнечного излучения в качестве источника теплового излучения. Солнечная энергетическая установка включает, по меньшей мере, один коллектор, теплоакуммулятор кратковременного хранения тепловой энергии, парогенератор, паровую турбину, конденсатор, причем теплоакуммулятор кратковременного хранения тепловой энергии заполнен высокотемпературной жидкостью, при этом установка включает первый замкнутый циркуляционный контур с высокотемпературным теплоносителем, в который последовательно включены коллектор и теплоакуммулятор кратковременного хранения тепловой энергии, причем первый контур содержит теплообменник, расположенный в теплоакуммуляторе кратковременного хранения тепловой энергии, второй - замкнутый циркуляционный контур с высокотемпературной жидкостью, в который последовательно включены теплоакуммулятор кратковременного хранения тепловой энергии и парогенератор, причем второй контур содержит два теплообменника, расположенные, соответственно, в теплоакуммуляторе кратковременного хранения тепловой энергии и в парогенераторе, заполненном высокотемпературной жидкостью, третий - замкнутый циркуляционный контур с низкокипящим рабочим веществом. Техническим результатом изобретения является увеличение эффективности преобразования солнечной энергии [15]. 
Также представляют интерес для спещиалистов следующие изобретения в области нанотехнологий:

- Способ модифицирования углеродных наноматериалов (RU 2548083) [16].

- Нановолокнистый полимерный материал (RU 2543377) [17].

- Способ приготовления наносуспензии для изготовления полимерного нанокомпозита (RU 2500695) [18].

- Способ упрочнения металлических изделий с получением наноструктурированных поверхностных слоев (RU 2527511) [19].

- Способ формирования жаростойкого нанокомпозитного покрытия на поверхности изделий из жаропрочных никелевых сплавов (RU 2549813) [20].

- Способ нанесения наноалмазного материала комбинированной электромеханической обработкой (RU 2530432) [21].

- Способ получения сажи, содержащей фуллерены и нанотрубки, из газообразного углеводородного сырья (RU 2531291) [22].

- Способ получения нанопорошков оксида цинка с поверхностным модифицированием для использования в строительных герметиках (RU 2505379) [23].

- Высокоресурсный электродуговой генератор низкотемпературной плазмы с защитным наноструктурированным углеродным покрытием электродов (RU 2541349) [24].

- Способ получения слоистого наноматериала (RU 2530456) [25].

- Тонкодисперсная органическая суспензия металл/углеродного нанокомпозита и способ ее изготовления (RU 2527218) [26].

- Способ получения нанопорошков металлов с повышенной запасенной энергией (RU 2535109) [27].

- Способ упрочнения металлических изделий с получением наноструктурированных поверхностных слоев (RU 2527511) [28]. 


\section{УВАЖАЕМЫЕ КОЛЛЕГИ!}

ПРИ ИСПОЛЬЗОВАНИИ МАТЕРИАЛА ДАННОЙ СТАТЬИ

ПРОСИМ ДЕЛАТЬ БИБЛИОГРАФИЧЕСКУЮ ССЫЛКУ НА НЕЁ:

Власов B.A. Обзор изобретений в области нанотехнологий и наноматериалов. Часть 3 // Нанотехнологии в строительстве. - 2015. - Том 7, № 5. - С. 64-82. DOI: dx.doi.org/10.15828/2075-8545-2015-7-5-64-82.

\section{DeAR COlleagues!}

THE REFERENCE TO THIS PAPER HAS THE FOLLOWING CITATION FORMAT:

Vlasov V.A. The review of patents in the area of nanotechnologies and nanomaterials. Part 3. Nanotehnologii v stroitel'stve $=$ Nanotechnologies in Construction. 2015, Vol. 7, no. 5, pp. 64-82. DOI: dx.doi.org/10.15828/2075-8545-2015-7-564-82. (In Russian).

\section{Библиографический список:}

1. Патенты и изобретения, зарегистрированные в РФ и СССР [Электронный ресурс]. - Режим доступа: http://www.findpatent.ru/patent/256/2561616.html (дата обращения: 25.08.15).

2. Патенты и изобретения, зарегистрированные в РФ и СССР [Электронный ресурс]. - Режим доступа: http://www. findpatent.ru/patent/256/2561614.html (дата обращения: 25.08.15).

3. Патенты и изобретения, зарегистрированные в РФ и СССР [Электронный ресурс]. - Режим доступа: http://www.findpatent.ru/patent/256/2561435.html (дата обращения: 25.08.15).

4. Патенты и изобретения, зарегистрированные в РФ и СССР [Электронный ресурс]. - Режим доступа: http://www.findpatent.ru/patent/256/2561379.html (дата обращения: 25.08.15).

5. Патенты и изобретения, зарегистрированные в РФ и СССР [Электронный ресурс]. - Режим доступа: http://www.findpatent.ru/patent/256/2561343.html (дата обращения: 25.08.15).

6. Патенты и изобретения, зарегистрированные в РФ и СССР [Электронный ресурс]. - Режим доступа: http://www.findpatent.ru/patent/256/2561267.html (дата обращения: 25.08.15). 
7. Патенты и изобретения, зарегистрированные в РФ и СССР [Электронный ресурс]. - Режим доступа: http://www.findpatent.ru/patent/256/2561170.html (дата обращения: 25.08.15).

8. Патенты и изобретения, зарегистрированные в РФ и СССР [Электронный ресурс]. - Режим доступа: http://www.findpatent.ru/patent/256/2560898.html (дата обращения: 25.08.15).

9. Патенты и изобретения, зарегистрированные в РФ и СССР [Электронный ресурс]. - Режим доступа: http://www.findpatent.ru/patent/256/2560722.html (дата обращения: 25.08.15).

10. Патенты и изобретения, зарегистрированные в РФ и СССР [Электронный ресурс]. - Режим доступа: http://www.findpatent.ru/patent/256/2560382.html (дата обращения: 25.08.15).

11. Патенты и изобретения, зарегистрированные в РФ и СССР [Электронный ресурс]. - Режим доступа: http://www.findpatent.ru/patent/256/2560031.html (дата обращения: 25.08.15).

12. Патенты и изобретения, зарегистрированные в РФ и СССР [Электронный ресурс]. - Режим доступа: http://www.findpatent.ru/patent/255/2559481.html (дата обращения: 25.08.15).

13. Патенты и изобретения, зарегистрированные в РФ и СССР [Электронный ресурс]. - Режим доступа: http://www.findpatent.ru/patent/255/2559351.html (дата обращения: 25.08.15).

14. Патенты и изобретения, зарегистрированные в РФ и СССР [Электронный ресурс]. - Режим доступа: http://www.findpatent.ru/patent/255/2559284.html (дата обращения: 25.08.15).

15. Патенты и изобретения, зарегистрированные в РФ и СССР [Электронный ресурс]. - Режим доступа: http://www.findpatent.ru/patent/255/2559093.html (дата обращения: 25.08.15).

16. Власов $B . A$. Обзор изобретений в области нанотехнологий и наноматериалов. Часть 2 // Нанотехнологии в строительстве. - 2015. - Том 7, № 4. - С. 59-79. DOI: dx.doi.org/10.15828/2075-8545-2015-7-4-59-79.

17. Патенты и изобретения, зарегистрированные в РФ и СССР [Электронный ресурс]. - Режим доступа: http://www.findpatent.ru/patent/254/2543377.html (дата обращения: 25.08.15).

18. Патенты и изобретения, зарегистрированные в РФ и СССР [Электронный ресурс]. - Режим доступа: http://www.findpatent.ru/patent/250/2500695.html (дата обращения: 25.08.15).

19. Власов B.A. Изобретения в области нанотехнологий позволяют добиться значительного эффекта в строительстве, жилищно-коммунальном хозяйстве, смежных отраслях экономики // Нанотехнологии в строительстве. - 2014. -Том 6, № 5. - C. 93-113. - DOI: dx.doi.org/10.15828/2075-8545-2014-6-5-93-113. 
20. Власов B.A. Обзор изобретений в области нанотехнологий и наноматериалов. Часть 2 // Нанотехнологии в строительстве. - 2015. - Том 7, № 4. - С. 59-79. DOI: dx.doi.org/10.15828/2075-8545-2015-7-4-59-79.

21. Патенты и изобретения, зарегистрированные в РФ и СССР [Электронный ресурс]. - Режим доступа: http://www.findpatent.ru/patent/253/2530432.html (дата обращения: 25.08.15).

22. Патенты и изобретения, зарегистрированные в РФ и СССР [Электронный ресурс]. - Режим доступа: http://www.findpatent.ru/patent/253/2530432.html (дата обращения: 25.08.15).

23. Патенты и изобретения, зарегистрированные в РФ и СССР [Электронный ресурс]. - Режим доступа: http://www.findpatent.ru/patent/250/2505379.html (дата обращения: 25.08.15).

24. Власов B.A. Обзор изобретений в области нанотехнологий и наноматериалов. Часть 1 // Нанотехнологии в строительстве. - 2015. - Том 7, № 2. - С. 89114. - DOI: dx.doi.org/10.15828/2075-8545-2015-7-2-89-114.

25. Власов B.A. Изобретения в области нанотехнологий позволяют в конечном итоге повысить конкурентоспособность продукции // Нанотехнологии в строительстве. - 2014. - Том 6, № 6. - С. 58-78. - DOI: dx.doi.org/10.15828/2075-85452014-6-6-58-78.

26. Патенты и изобретения, зарегистрированные в РФ и СССР [Электронный ресурс]. - Режим доступа: http://www.findpatent.ru/patent/252/2527218.html (дата обращения: 25.08.15).

27. Власов B.A. Изобретения в области нанотехнологий и наноматериалов позволяют добиться значительного эффекта в различных отраслях экономики // Нанотехнологии в строительстве. - 2015. - Том 7, № 1. - C. 82-104. - DOI:dx.doi. org/10.15828/2075-8545-2015-7-1-82-104.

28. Патенты и изобретения, зарегистрированные в РФ и СССР [Электронный ресурс]. - Режим доступа: http://www.findpatent.ru/patent/252/2527511.html (дата обращения: 25.08.15). 